Andreas Öchsner

\title{
Introduction to Scientific Publishing
}

Backgrounds, Concepts, Strategies 


\section{Contents}

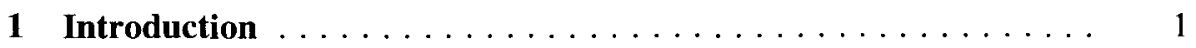

References ........................ 2

2 Technical and Cognitive Skills in the Context

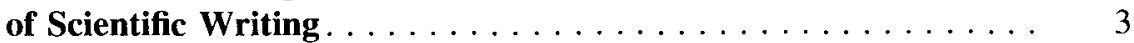

2.1 Technical and Cognitive Skills . . . . . . . . . . . . 3

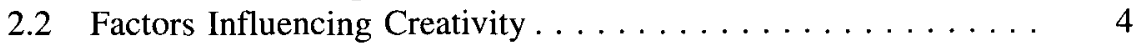

References ....................... 6

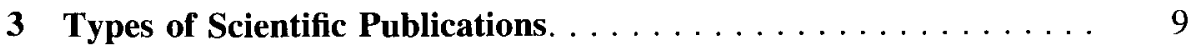

3.1 Overview . . . . . . . . . . . . . . . . . . . 9

3.2 Assessment of the Different Forms of Scientific Publications ... 14

3.3 Identification of Publications: ISBN, ISSN, and DOI . . . . . 16

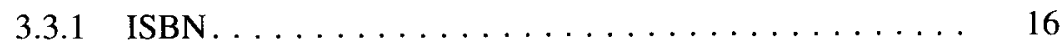

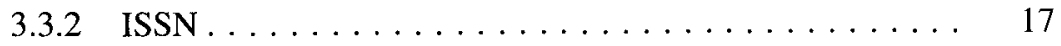

3.3 .3 DOI. . . . . . . . . . . . . . . . . . 19

References ......................... 21

4 Publishing Companies, Publishing Fees, and Open

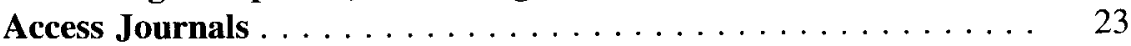

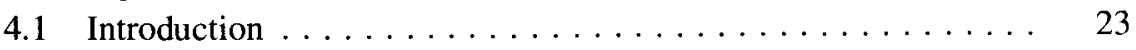

4.2 Costs of Journal Publishing. . . . . . . . . . . . . 24

4.3 Bearing the Costs of Journal Publishing: Business Models . . . . 26

References . . . . . . . . . . . . . . . . . . . . . . . . 29

5 Abstract and Index Databases (Web of Knowledge,

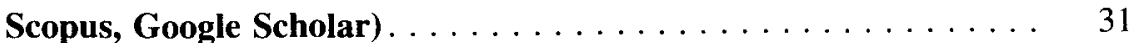

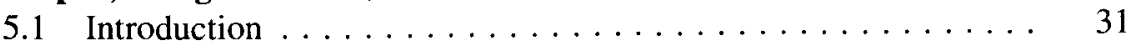

5.2 Web of Knowledge .................... 31

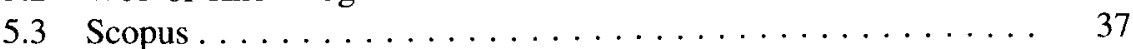

5.4 Google Scholar . . . . . . . . . . . . . . . . . . . . . 39 
5.5 Comparison of the Databases . . . . . . . . . . . . 44

References $\ldots \ldots \ldots \ldots \ldots \ldots \ldots \ldots \ldots$

6 Statistical Evaluation of Bibliographical Data: Evaluation

of Journals, Scientists, and Institutions . . . . . . . . . . . . . 47

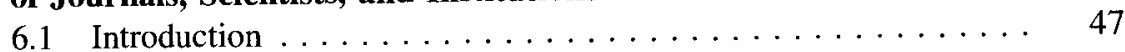

6.2 Impact Factor $\ldots \ldots \ldots \ldots \ldots \ldots \ldots \ldots \ldots \ldots \ldots \ldots$

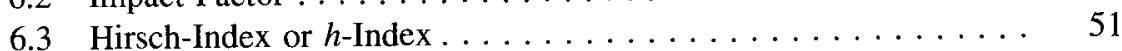

6.4 Other Bibliometric Measures. . . . . . . . . . . . . . . 54

6.5 Evaluation of Research and Scientists . . . . . . . . . . . . 56

6.6 International University Rankings . . . . . . . . . . . . . 60

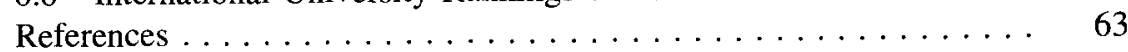

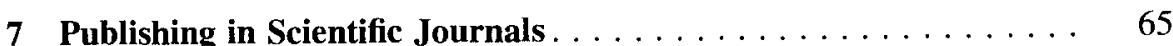

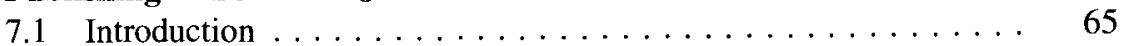

7.2 Time Frame of Publication . . . . . . . . . . . . . 66

7.3 Peer-Review Approaches . . . . . . . . . . . . . . 69

7.4 The Basic Structure of a Manuscript . . . . . . . . . . 71

7.4 .1 Manuscript Title . . . . . . . . . . . . . . . 71

7.4 .2 Authors ...................... 72

7.4 .3 Abstract ...................... 72

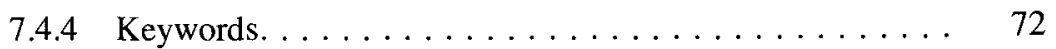

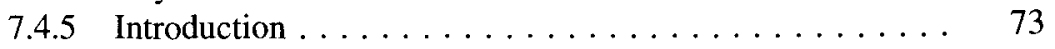

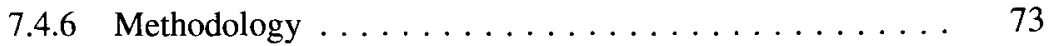

7.4 .7 Results and Discussion . . . . . . . . . . . . . . 74

7.4 .8 Literature Section . . . . . . . . . . . . . . . . 74

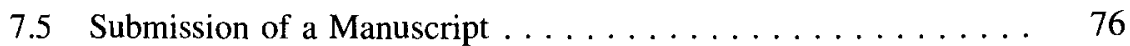

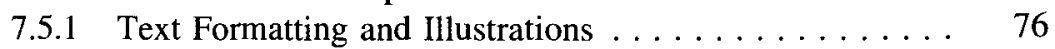

7.5 .2 Cover Letter. . . . . . . . . . . . . . . . . . . . 79

7.5.3 Recommending Reviewers . . . . . . . . . . . . . 80

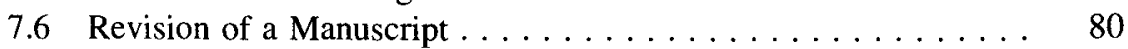

References ........................... 81

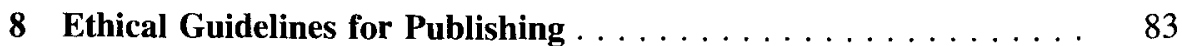

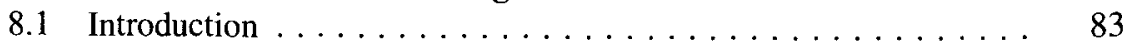

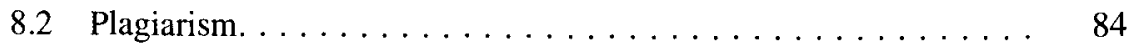

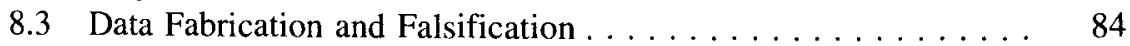

8.4 Multiple Submission . . . . . . . . . . . . . . . . . . . . 84

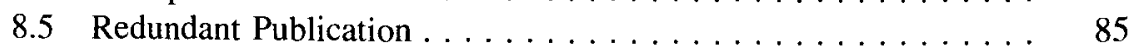

8.6 Authorship . . . . . . . . . . . . . . . . . . . 85

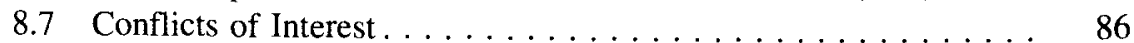

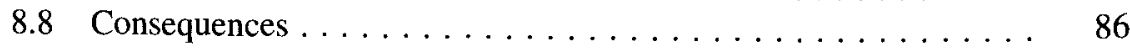

References ....................... 87 
9 Strategies to Publish $\ldots \ldots \ldots \ldots \ldots \ldots \ldots \ldots \ldots \ldots \ldots$

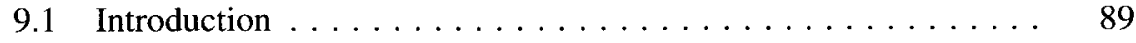

9.2 Journal Selection Process . . . . . . . . . . . . . . . . 91

References ......................... 91

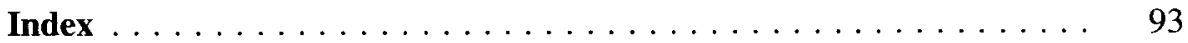

